\title{
Antifungal peptides secreted by filamentous fungi as promising new agents in human therapy
}
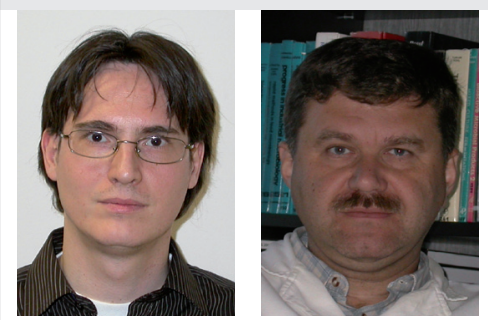

\author{
"Further studies are now needed to \\ prove the practical efficiency of \\ antimicrobial peptides secreted by \\ filamentous fungi."
}

László Galgóczy† \& Csaba Vágvölgyi

†Author for correspondence: Department of Microbiology, Faculty of Sciences \& Informatics, University of Szeged, Közép fasor 52, H-6726, Hungary = Tel. : +36 62544005 = Fax: +36 62544823 = galgoczi@gmail.com

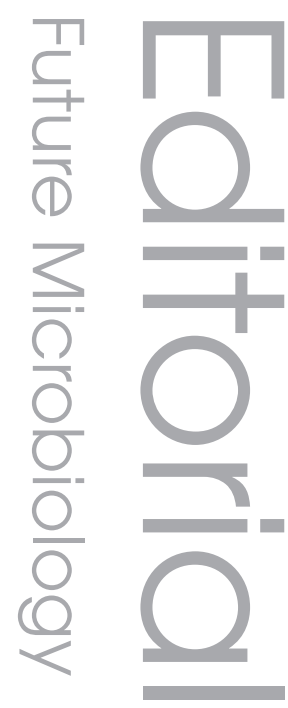

The incidence of fungal infections has increased continuously during recent years due to increasing number of immunocompromised hosts and the emergence of antibiotic-resistant strains. There is a substantial demand for new compounds with antimicrobial activity. While some newer agents (e.g., SPK-843, a novel polyene) have reduced toxicity and are easy to use, the most widely used antifungal drugs (e.g., amphotericin B) are quite toxic and have serious side effects [1]. Furthermore, many filamentous fungi are destructive pathogens of plants and are thus responsible for enormous crop losses worldwide. Therefore, peptides with a similar structure to defensins are interesting in this respect, as they have effective inhibitory activity against both bacteria and fungi.

Defensins, part of the innate immune system, were discovered in the early 1980s in higher organisms [2,3]. They are small, cysteine-rich, cationic peptides with a broad antimicrobial spectrum and varied mechanisms of action $[2,4-6]$. They have three major targets in sensitive organisms: the cell wall, cell membrane and intracellular organelles [2,4]. There are over 500 cationic membrane-acting proteins with antibacterial and antifungal activities that have been identified to date [2].

Antimicrobial peptides secreted by some filamentous fungi have a low molecular mass (5.1-6.6 kDa), are basic and contain 6-8 cysteine residues and several disulfide bonds. Proteins with such properties with antifungal activity have been isolated from four fungal species belonging to the Ascomycetes (Penicillium chrysogenum, Penicillium nalgiovense, Aspergillus giganteus and Aspergillus niger), furthermore, in silico investigation of genomic databases has revealed putative proteins with high homology to those already isolated, in Gibberella zeae,
Aspergillus clavatus and Neosartorya fischeri $[7,8]$. The 5'-upstream regions of $A$. giganteus antifungal protein (AFP)- and P. chrysogenum antifungal protein (PAF)-encoding genes contain several putative binding sites for fungal transcription factors that might be involved in the transcriptional regulation of both genes in response to environmental signals and stress (e.g., stress elements, carbon catabolite repressor, heat-shock motif, GATA factor-and pH-regulatory factorbinding sites) [7]. The level of protein production is affected by different environmental factors, such as carbon starvation, the presence of excess $\mathrm{NaCl}$ or ethanol and heat-shock [7]. PAF and AFP are the most intensively studied fungusderived antifungal peptides. It has been shown that, in sensitive fungi, PAF is internalized by receptor-mediated endocytosis and exerts multiple detrimental effects: induction of morphological changes, membrane perturbation, intracellular oxidative stress and apoptosis [9-11]. It is hypothesized that PAF acts via a G-protein signal transduction pathway, but the exact mechanism has not yet been elucidated [11]. In susceptible organisms a small proportion of the applied AFP binds electrostatically to the cell membrane and induces pore formation. A large amount of AFP accumulates in the cell wall, digesting it; furthermore, AFP inhibits chitin synthesis [12-14]. In in vitro experiments it has been demonstrated that AFP binds to DNA via an oligonucleotide/oligosaccharide binding motif and causes the chromatin to condense [15]. AFP is a highly stable - it has been shown to preserve its antifungal activity up to 14 days after application [16]. Previous studies suggest that antifungal proteins secreted by taxonomically distinct species have different modes of action and species specificity, nevertheless their structure is very similar [7]. 
The effects of filamentous fungi-derived antifungal peptides have only been investigated in a very limited number of filamentous fungal isolates to date. They have a narrow antimicrobial spectrum, but their species specificity is different [7]. AFP and PAF treatment results in strong antifungal effects in the case of some opportunistic human and/or plant pathogens belonging to the Ascomycetes and Zygomycetes $[7,17,18]$. This inhibition acts by disrupting sporangium and conidium formation, the germination of sporangiospores and conidia and/or hyphal extension. Treated mycelia are swollen and short, with multiple branches and spores displaying abnormal and delayed germination when cultivated in antifungal peptide-containing medium [9,16]. Activity against yeasts has not been reported for any of the above-mentioned antifungal proteins so far and only $A$. niger antifungal protein inhibited growth of Candida albicans, Saccharomyces cerevisiae and Trichosporon beigelii [7]. It may be hypothesized that a combined application of different species-specific antifungal peptides against fungal infection represents a promising novel broad-spectrum antifungal therapy or fungicide.

AFP and PAF do not have any toxic effects on mammalian cells, do not modify voltage-gated potassium channels of neurons, skeletal muscle fibers or astrocytes and do not induce the production of proinflammatory cytokines in the intended therapeutic concentration $(2-100 \mu \mathrm{g} / \mathrm{ml})$ in vitro $[19,20]$ further demonstrating their potential as antifungal therapeutics. Their ability to act synergistically with other drugs and antifungal peptides has been revealed. PAF acts synergistically with statins and fluconazole, and such treatment exhibits potent antifungal activity against different zygomycetes and dermatophyte isolates $[21,22]$. An additive effect against the plant pathogenic fungus Botrytis cinerea was observed when AFP was combined with cecropin A, which is an antifungal peptide isolated from a Cecropia moth [16].

Several antimicrobial peptides serve as the basis for the design of new synthetic analogs. Both the peptides and their analogs have been expressed in transgenic plants to confer disease protection or are secreted by microorganisms to be used as active ingredients of commercial biopesticides and medicines $[2,8,23]$. Antimicrobial proteins from filamentous fungi, which are secreted in high abundance into the supernatant of easily fermentable molds, are promising compounds in medicine and agriculture; furthermore their safety, sustainability, high efficacy, limited toxicity and low costs of production could make them favorable $[7,8,23]$.

Further studies are now needed to prove the practical efficiency of antimicrobial peptides secreted by filamentous fungi, for example, animal and plant model experiments to reveal their toxicity in vivo, examination of interaction between antifungal peptides and other drugs or pesticides, investigation of their pharmacokinetic properties and their effects on higher organisms.

\section{Financial \& competing interests disclosure \\ The authors have no relevant affiliations or financial involvement with any organization or entity with a financial interest in or financial conflict with the sub- ject matter or materials discussed in the manuscript. This includes employment, consultancies, honoraria, stock ownership or options, expert testimony, grants or patents received or pending, or royalties. \\ No writing assistance was utilized in the production of this manuscript.}

\section{Bibliography}

1. Kakeya H, Miyazaki Y, Senda H et al: Efficacy of SPK-843, a novel polyene antifungal, in comparison with amphotericin B, liposomal amphotericin B, and micafungin against murine pulmonary aspergillosis. Antimicrob. Agents Chemother. 52(5), 1868-1870 (2008).

2. Theis T, Stahl U: Antifungal proteins: targets, mechanisms and prospective applications. Cell. Mol. Life Sci. 61(4), 437-455 (2004).

3. Jenssen H, Hamill P, Hancock REW: Peptide antimicrobial agents. Clin. Microbiol. Rev. 19(3), 491-511 (2006).

4. Yeaman MR, Yount NY: Mechanisms of antimicrobial peptide action and resistance. Pharm. Rev. 55(1), 27-55 (2003).
5. Ganz T: Defensins: antimicrobial peptides of innate immunity. Nature Rev. Immunol. 3(9), 710-720 (2003).

6. Brown KL, Hancock REW: Cationic host defense (antimicrobial) peptides. Curr. Opin. Immunol. 18(1), 24-30 (2006).

7. Marx F: Small, basic antifungal proteins secreted from filamentous ascomycetes: a comparative study regarding expression, structure, function and potential application. Appl. Microbiol. Biotechnol. 65(2), 133-142 (2004).

8. Meyer V: A small protein that fights fungi: AFP as a new promising antifungal agent of biotechnological value. Appl. Microbiol. Biotechnol. 78(1), 17-28 (2008).
9. Kaiserer L, Oberparleiter C, Weiler-Görz R, Burgstaller W, Leiter É, Marx F: Characterization of the Penicillium chrysogenum antifungal protein PAF. Arch. Microbiol. 180(3), 204-210 (2003).

10. Leiter É, Szappanos H, Oberparleiter C et al.: Antifungal protein PAF severely affects the integrity of the plasma membrane of Aspergillus nidulans and induces an apoptosislike phenotype. Antimicrob. Agents Chemother. 49(6), 2445-2453 (2005).

11. Marx F, Binder U, Leiter É, Pócsi I: The Penicillium chrysogenum antifungal protein PAF, a promising tool for the development of new antifungal therapies and fungal cell biology studies. Cell. Mol. Life. Sci. 65(3), 445-454 (2008). 
12. Theis T, Wedde M, Meyer V, Stahl U: The antifungal protein from Aspergillus giganteus causes membrane permeabilization. Antimicrob. Agents Chemother. 47(2), 588-593 (2003).

13. Theis T, Marx F, Salvenmoser W, Stahl U, Meyer V: New insights into the target site and mode of action of the antifungal protein of Aspergillus giganteus. Res. Microbiol. 156(1), 47-56 (2005).

14. Hagen S, Marx F, Ram AF, Meyer V: The antifungal protein AFP from Aspergillus giganteus inhibits chitin synthesis in sensitive fungi. Appl. Environ. Microbiol. 73(7), 2128-2134 (2007).

15. del Pozo ÁM, Lacadena V, Mancheno JM, Olmo N, Onaderra M, Gavilanes JG: The antifungal protein AFP of Aspergillus giganteus is an oligonucleotide/ oligosaccharide binding (OB) fold-containing protein that produces condensation of DNA. J. Biol. Chem. 277(48), 46179-46183 (2002).

16. Moreno AB, del Pozo ÁM, Borja M, San Segudo B: Activity of the antifungal protein from Aspergillus giganteus against Botrytis cinerea. Phytopathology 93(11), 1344-1353 (2003).
17. Barna B, Leiter É, Hegedus N, Bíró T, Pócsi I: Effect of the Penicillium chrysogenum antifungal protein (PAF) on barley powdery mildew and wheat leaf rust pathogens. J. Basic Microbiol. 48(6), 516-520 (2008).

18. Galgóczy L, Papp T, Leiter É, Marx F, Pócsi I, Vágvölgyi CS: Sensitivity of different Zygomycetes to the Penicillium chrysogenum antifungal protein (PAF). J. Basic Microbiol. 45(2), 136-141 (2005).

19. Szappanos H, Szigeti GP, Pál B et al.: The Penicillium chrysogenum-derived antifungal peptide shows no toxic effects on mammalian cells in the intended therapeutic concentration. Naunyn-Schmiedeberg's Arch. Pharmacol. 371(2), 122-132 (2005).

20. Szappanos H, Szigeti GP, Pál B et al.: The antifungal protein AFP secreted by Aspergillus giganteus does not cause detrimental effects on certain mammalian cells. Peptides 27(7), 1717-1725 (2006).

21. Galgóczy L, Papp T, Lukács G, Leiter É, Pócsi I, Vágvölgyi CS: Interactions between statins and Penicillium chrysogenum antifungal protein (PAF) to inhibit the germination of sporangiospores of different sensitive Zygomycetes. FEMS Microbiol. Lett. 270(1), 109-115 (2007).
22. Galgóczy L, Papp T, Pócsi I, Hegedus N, Vágvölgyi CS: In vitro activity of Penicillium chrysogenum antifungal protein (PAF) and its combination with fluconazole against different dermatophytes. Anton. Leeuw. Int. J. G. Microbiol. 94(3), 463-470 (2008).

23. Montesinos E: Antimicrobial peptides and plant disease control. FEMS Microbiol. Lett. 270(1), 1-11 (2007).

\section{Affiliations}

\section{- László Galgóczy}

Department of Microbiology, Faculty of Sciences \& Informatics, University of Szeged, Közép fasor 52, H-6726, Hungary Tel.: +36 62544005 ;

Fax: +36 6254 4823; galgoczi@gmail.com

- Csaba Vágvölgyi Department of Microbiology, Faculty of Sciences \& Informatics, University of Szeged, Közép fasor 52, H-6726, Hungary Tel.: +36 62544005 ;

Fax: +36 6254 4823;

csaba@bio.u-szeged.hu 